\title{
JUDICIOUS USE OF L1: A SOCIOCULTURAL INVESTIGATION OF TEACHERS' USE OF L1 IN 22 CLASSROOMS
}

\author{
Fatemeh Khonamri \& Farzam Khonamri \\ University of Mazandaran \\ fkhonamri@umz.ac.ir
}

First draft received: 24 May 2017

Final proof received: 20 August 2017

\begin{abstract}
This study is a sociocultural investigation of the reasons why teachers use L1 in L2 classes through different classroom "modes" (Walsh, 2011). So far, a few studies regarding L1 have focused on L1 use in different classroom contexts, and none have used Walsh's model of classroom modes. To this end, the present study used Walsh's model which quarters the classroom context along with the Conversation Analysis techniques, to meticulously examine the classroom interactions. The classes were chosen from three different teachers in Mazandaran, Iran. A total of 6 sessions were recorded and transcribed. Results suggest that teachers use L1 mostly for managing purposes: drawing students' attention, and making sure they have comprehended what they are supposed to do, and educational purposes: explaining difficult grammar and vocabulary, and eliciting desired structures or utterances. These findings might help teachers use L1 more efficiently and judiciously, instead of avoiding it when and where it might benefit the learners, as well as minimizing it in their classes as much as possible.
\end{abstract}

Keywords: sociocultural theory; conversation analysis; L1 use; classroom modes.

To cite this paper (in APA style):

Khonamri, F., \& Khonamri, F. (2017). Judicious use of L1: A sociocultural investigation of teachers' use of L1 in L2 classrooms. International Journal of Education, 10(1), 34-45. doi: http://dx.doi.org/10.17509/ije.v10i1.7646

\section{INTRODUCTION}

This study investigates one of the thorniest issues in second language (L2) pedagogy. The use of L1 in second language teaching and learning has been looked upon so negatively that some theoreticians even suggested banning it from L2 classes. Amongst these theoreticians are Krashen and Long. The ideology these theoreticians and their proponents adopt claims that to learn an L2 one has to be exposed to it as much as possible. At its strongest, this maximum exposure to the $\mathrm{L} 2$ has been translated to the total exclusion of $\mathrm{L} 1$ in L2 classrooms, or as Cook (2001) puts it "Ban[ning] the L1 from the classroom" (p. 404). The roots of this animosity can be traced back to the time of the "Great Reform" of the late nineteenth century (Hawkins, 1987, as cited in Cook, 2001) when aversion toward Grammar-Translation Method (GTM) resulted in the introduction of methodologies such as the Direct Method (DM), Audio-Lingual Method (ALM) and the like. The success of these methods compounded the animosity and made people believe that the best way to learn a language is the procedure these methodologies take_the "monolingual principle."
However, this has not been the case for everyone. There were still people who believed L1 could be a useful instrument in the hands of the teachers in L2 classrooms. And indeed it has been (Cook, 2001). In addition, research has proven that, despite the dominance of this ideology of "anti-L1ism" in L2 pedagogy, the existence of $\mathrm{L} 1$ in $\mathrm{L} 2$ classrooms is inevitable in EFL contexts (Chen \& Hird, 2006; Cook, 2001; Song, 2009). Although the monolingual principle enjoys popularity and dominance in $\mathrm{L} 2$ education, it seems it has only been partially implemented into practice (Song, 2009), and according to Warford (2007) only around $50 \%$ of the class time (Allen, 2002; Warford, 2007; Wing, 1980; Wong, 2005) or less (Calman \& Daniel, 1998; Shapson, Kaufman, \& Durward, 1978) has been in L2 in North America (all cited in, Warford, 2007). Apparently, the monolingual principle seems only possible in situations where either the teacher does not speak the language of the learners or the learners come from different L1 backgrounds. One of the theories taking a position against this monolingual principle is the Vygotskian sociocultural theory (SCT). This is particularly evident in the 
sociocultural view of L1 as a "scaffolding tool" (Antón \& DiCamilla, 1998; Brooks-Lewis, 2009). In SCT, (language) learning is a social phenomenon which is achieved through collaborative dialogue, and L1 is just another tool which facilitates this dialogue, and thus improves learning. But the problem which arises here is what Wells (1998) has cautioned the teachers about: the extensive use of $\mathrm{L} 1$. This is of high importance since the class is the main, if not the only, source for the learners. The debates over the "judicious" use of $L 1$ have been simmering for years, but determining a balance between the use of $L 1$ versus $L 2$ in a classroom seems to be impossible due to the lack of definitive research (Turnbull \& Arnett, 2002). One way to solve this issue might be recognizing the existence of different micro-context in the classroom with their specific interactional features.

Until recently, the studies on L1 have mostly been on the basis of questions asked from the teachers and/or students about their opinions on whether or not it is a good idea to use L1 in L2 classes (Mora Pablo, Lengeling, Rubio Zenil, Crawford, \& Goodwin, 2011). The issue with these kinds of studies might be that they do not actually capture what really goes on in the classroom and it makes it next to impossible to verify what the teachers and students claimed, and prove any of the conclusions drawn. To go around this issue, some studies have used Conversation Analysis (CA) to capture what goes on in the classroom and base their conclusions on these documented evidences (De $\mathrm{La}$ Campa \& Nassaji, 2009; Samar \& Moradkhani, 2014).

De La Campa and Nassaji (2009) carried out a study on a German-as-a-second-language classroom to examine the amount, the purposes, and the reasons of L1 use, and concluded that the two teachers under study did not differ significantly in their portion of use of $\mathrm{L} 1$ and that they used it for a variety of purposes. They used L1 not only to teach L2 but also to make classroom environment enjoyable. The average amount of L1 used in these classes was $11.3 \%$ for the whole classes. In a more recent study, Samar and Moradkhani (2014) investigated the reasons for teachers codeswitching in L2 classrooms in an EFL context. They came up with eight reasons why teachers use L1: the most frequently cited reason was students' better comprehension. The second one was to check students' comprehension. Other reasons were using the L1 for explaining grammar; comparing and contrasting L1 and L2; using L1 for students' emotional well-being; students' lack of comprehensibility; students' proficiency level; and finally, efficiency.

But what they seem to miss in their studies is to ask this question that "Is the classroom context an indivisible entity or it consists of different micro- contexts? Are the classroom interactions of the same type through the class time or they differ? These are the questions Üstünel and Seedhouse (2005) made sure not to miss. They carried out a study on six conversation classes at a Turkish university, investigating the sequential organization of "teacher initiated" and "teacher induced" code-switching and came up with three preference organization patterns: (a) teachers code-switched after a pause of more than one second in response to a question in $L 2$ and not receiving any reply; (b) teachers code-switched to $L 1$ to encourage learners to produce turns in L2; and finally, (c) teacher-induced code-switching. Teachers asked students to translate to $\mathrm{L} 1$ their $\mathrm{L} 2$ utterances to make sure the students have understood the teachers.

Indeed, there seems to be two approaches for answering the above questions. The one Seedhouse (2004) adopts, which suggests that the classroom context consists of four micro-contexts, namely (a) form-and-accuracy context, (b) meaning-and-fluency context, (c) task-oriented context, and (d) procedural context. And the one Walsh (2011) adopts, which argues that the classroom context comprises four "modes," namely (a) managerial mode, (b) material mode, (c) skills and system mode, and (d) classroom context mode.

The managerial mode "accounts for what goes on in the organization of learning. Its prime pedagogic goal is to organize learning in time and space and to set up or conclude classroom activities" (Walsh, 2011, pp. 113-114). The materials mode is mainly focused on the materials being used, which is mostly the course book. The skills and systems mode is the mode whose goal is "providing language practice in relation to a particular language system or language skill" (Walsh, 2011, p. 118). The classroom context mode is the mode in which "opportunities for genuine communication are frequent and the teacher plays a less prominent role, taking more of a 'back seat' and allowing learners all the interactional space they need" (Walsh, 2011, p. 121, italics mine).

This study, using CA and Walsh's (2011) model of classroom modes, is intended to investigate teachers' purposes of use of L1 in L2 classroom, and investigate the correspondence of $\mathrm{L} 1$ use with the pedagogical focus of the particular classroom "mode" it was used in. The results of this study could be significant in a way that it might help teachers not only avoid repelling L1 but to manipulate it "judiciously" in their own and their students' benefits. 


\section{METHODOLOGY}

The present study takes a qualitative approach toward data collection and uses Conversation Analysis (CA) for analyzing the data. CA is a methodology for studying and analyzing naturally-occurring spoken interactions, and a powerful instrument in service of SCT. One reason to use $C A$ in this study is because, unlike interviews, it captures what really goes on in the classroom and not what teachers and students think has happened. Hence, it enjoys a higher validity than interviews and recall sessions, which might not be so accurate. What one, even in an interview right after the class, thinks has happened might be, by far, different from what really has happened. CA records as many bits and pieces of interactions as possible, so as to make the judgments on what has gone on as objective as possible. Another reason to opt for CA in this study is its alignment and congruence with the sociocultural framework.

Although CA was originally a sociological issue, it has been used in other disciplines such as linguistics, sociology and ethnomethodology as well. CA, in a broader sense, "refers to any study of people talking together" (Ten Have, 2007, p. 6). It is a multidisciplinary methodology and has been widely used in many different academic areas including second language learning and teaching. Despite the fact that Conversation Analysis is an approach in its own right, with its own theories and logics, SCT views it as just a tool in service of different sociocultural theories of learning (Markee \& Kasper, 2004). CA has been used in SCT paradigm as a powerful tool for analyzing the nuances of the interactions, and consequently better understanding them. Since this study uses the SCT framework as the theoretical backbone, and aims to base its claims on concrete and provable evidences, the best method to analyze the data of this study is considered to be Conversation Analysis.

CA studies may be questioned regarding their reliability as they do not present their primary data to the readers. Hence the reliability of major parts of their analyses is not available for examination (Seedhouse, 2005). On the other hand, however, CA analysts display their analyses so transparently as if giving the reader a tour, in a sense, of the processes of the analysis. They take the hand of the reader and walk them through all the stages of analysis step by step. This, of course, enables the readers to analyze the data themselves and judge the trustworthiness of the analysts' interpretations. Therefore, all the analyses are replicable to the readers themselves.

In case of validity (internal validity), it could be argued that CA studies are internally valid: the data depicts what the researcher(s) claim. This is due to its emic perspective of CA studies. As participants in an interaction produce signals that are comprehensible for the receiving end (the other participant or participants), so, taking an emic perspective puts the analysts in the receiving end of the signals produced. Being on the receiving end, the researcher(s) interpret what any other possible participant, to whom the signals are addressed, would.

The question still remains, however, that to what extend CA findings are generalizable (external validity). It is not far-fetched to assert that CA deals with both particular and general at the same time. Schegloff's (1968, as cited in Ten Have, 2007), introduction of 'distribution rule for first utterance,' for example, seems very generalizable to most telephone conversations. So is Wong (2002) sequence types occurring typically in American English telephone conversations, or Seedhouse (2004) argument about the relationship between interaction and pedagogy. They all, though discussing some specific cases, can be generalized to other similar situations and instances. Therefore, CA can be considered not only a study of different cases, but also that the finding from those cases are pretty much generalizable to other cases as well.

\section{Data collection}

The data of this study were gathered from three different teachers in two different cities of the province of Mazandaran, Iran. Table 1 below demonstrates some information about these three teachers. It goes without saying that all these teachers share a common L1 with the students. The classes were video-taped either with the institute's own CCTV cameras placed in the classes, or with my own camera shooting the class, accompanied by the institute's CCTV cameras capturing the class from opposite sides in order for having a better picture and hence a better understanding of what goes on in the classroom. A total of 15 sessions were recorded (5 consecutive sessions for each teacher) from which only the last two sessions were selected. The first three sessions were excluded in order to reduce the Hawthorne effect. In order to observe a balance in the data, the same procedure was also taken for the classes in which the researcher was not present and the whole class was video-recorded by the CCTVs. The classes were transcribed, mostly, using Jefferson (1983) model of transcription. The transcripts, then, based on their interactional features, were coded into different modes, according to Walsh's (2011) model of modes. These transcripts were analyzed 3 times with 4 months intervals to verify the intra-rater reliability of the codings. That is, to make 
sure the interpretations from them were unbiased and remained the same through the course of time.

Due to the qualitative nature of this study, and to provide more meticulous information, the qualitative Table 1

\begin{tabular}{cccclcc}
\hline & Age & Sex & $\begin{array}{c}\text { Years of } \\
\text { Experience }\end{array}$ & \multicolumn{1}{c}{ Degree and Field of Study } & $\begin{array}{c}\text { Level of } \\
\text { Teaching }\end{array}$ \\
\hline Teacher 1 & 29 & Female & 5 & $\begin{array}{l}\text { B.A.: English Language and Literature } \\
\text { M.A.: TEFL }\end{array}$ & $\begin{array}{c}\text { Lower } \\
\text { Intermediate }\end{array}$ \\
\hline Teacher 2 & 30 & Female & 7 & $\begin{array}{l}\text { B.A.: English Translation } \\
\text { M.A.: TEFL }\end{array}$ & $\begin{array}{c}\text { Lower } \\
\text { Intermediate }\end{array}$ \\
\hline Teacher 3 & 27 & Male & 3 & $\begin{array}{l}\text { B.A.: English Language and Literature } \\
\text { M.A.: English Literature }\end{array}$ & $\begin{array}{c}\text { Lower } \\
\text { Intermediate }\end{array}$ \\
\hline
\end{tabular}

\section{Data analysis and discussion}

One mode in which the use of L1 was more conspicuous and abundant than others was the managerial mode. When teachers wanted to organize the class or when they wanted to attract students' attention to a point, for example, on how they should carry out an exercise, they preferred to use L1 to avoid any misunderstandings for the students and consequently their following requests for clarifications on what they were supposed to do and how they were supposed to do the exercise. The following is an example of such instances that teachers used L1 in order to make sure no more misunderstandings are going to happen in the future.

\section{Extract 1 (Teacher 1)}

1. T: you were supposed to interview one of your friends or family members.

2. Ss: (inaudible)

3. S1: Ms. TEACHER /tr.: I have written a conversation instead of an interview,.. er.. is there a problem?/

4. Ss: (inaudible)

5. T: /tr.: who else has done his/her homework incorrectly?/

6. S2: /tr.: I'm not sure if I have done it correctly or not/

7. S3: /tr.: I have definitely done them all incorrectly/

8. S4: /tr.: may I, I didn't do it because I had absolutely no idea on what to do/

9. T: /tr.: from now on, everybody has to listen carefully when we are talking about the homework. Who didn't understand it should say it right away so that their problem would be solved immediately. It is unacceptable if you come the next session and tell me that you didn't understand what you were supposed to do, or you did mistakenly. Then don't get upset with me when I made some data research software of NVIVO 8 was used to determine the percentage of each mode, and the percentage of $\mathrm{L} 1$ and $\mathrm{L} 2$ use in each mode. decisions about you. It is not a threat, but when I tell you something you are not listening at all. Don't say she is a strict teacher... it is going to be a mutual relationship. If the teacher treats you well, then you have to do your work well, too. Just study your lessons, just that. If it was going to be a one way relation that I come here and teach you and receive no feedback from you, then I wouldn't teach either. Why should I teach? Make myself tired?... ok. I said it in Farsi so that you don't forget it and also you understand it completely./

Extract 1 is an extract from one of the classes of Teacher 1 and it takes place in the first 10 minutes of the class. The teacher had assigned the students some homework in the previous session, but almost no student did it, or if they have, they mostly did it incorrectly. So the teacher started a long turn (turn 9) to solve the issue once and for all. The teacher, as she stated it at the end of her turn, /l said it in Farsi so that you don't forget it and also you understand it completely./, used Farsi (L1) so that the students could understand completely what she said to them and not to forget it. Her choice of language, according to her own accounts was of twofold: She assumed that if she had said it in English the students would not have noticed as much and consequently they would forget it. So she opted for Farsi so as to attract students' attentions so that they would not forget. And that was only, and only if they had understood the teacher in the first place.

Hence the second reason was to make the students understand what she told them. This is evident in turn 6, when S2 states /tr.: I'm not sure if I have done it correctly or not/, and turn 7, where S3, quite confidently, states that she has definitely done them all incorrectly. These two turns depicts that these students, at least, have not comprehended the teacher's demands which were pronounced in English in the previous session (Extract 2). Therefore, the teacher, 
due to the fact that her pronouncing the homework in English in the previous session had caused the preceding interactions to take place, assumed that if she says it in English the students might misunderstand her again, and do something that is not the preferred action she expects. Consequently, she used L1 to make sure the affiliation of students' response with her demand. By using Farsi she wanted to make sure no one is going to make the same mistake ever again.

Her reasons, as she herself uttered, was to attract the students' attention to what she told them (managing the classroom environment), and also to make sure they would comprehend what she said entirely. These uttered and inferred claims are in line with the literature regarding L1. Kraemer (2006), for instance, identifies eight functions for L1 use by teachers in L2 classes of which using L1 for classroom management is one of the most frequently stated purposes. Rolin-lanziti and Brownlie (2002), too, as a part of their findings stated that teachers use L1 for classroom management. Samar and Moradkhani (2014), among others, have counted different purposes for using L 1 in $L 2$ classes by teachers. Students' better comprehension, according to them, was the most frequently stated purpose of using L1. This, of course, verifies the second reason mentioned above for using $\mathrm{L} 1$ by the teacher. Mitchell (1988, as cited in Littlewood \& Yu, 2011), as another example, reports on the disciplinary aspect of $L 1$ use by the teachers as one of the two most common reasons for using L1.

We cannot, however, ignore the fact that first; she could have said what she said in English and then translated it into Farsi. But she did not do so. That, arguably, could be inferred as her reluctance to spend so much time on that and in a sense "waste the classroom time." As Atkinson (1987) notes, using L1 is a valuable technique for exploiting the class time. Therefore, she went straight for the $L 1$ so that she could save more time on what she had to cover during that session.

We cannot also ignore the fact that there still could be another reason other than the abovementioned, and that is the teacher's inability to state what she said in English. This assumption, however, seems very improbable due to the teacher's experience and knowledge of English that she could not utter those sentences in English. Nonetheless, it remains unproven, because the teacher was not afterwards asked to reproduce the utterances in English.

Extract 2 is the last minutes of the session preceding the session in which Extract 1 took place. This is the session in which the teacher announced the homework for the next session.

\section{Extract 2 (Teacher 1)}

1. $\mathrm{T}$ : for the next session do the exercises of your workbooks

$\rightarrow /$ tr.: and the other thing you should do/

The interview. Listen. Interview one of your friends or family members about TV shows. What's her favorite TV show, what doesn't he like, why. He/she, whatever. And what's your idea. Do you agree with him or not. Do you disagree with him or not.

2. S1: er.. write?

3. T: /tr.: of course/

As the extract displays Teacher 1 used English (L2) for announcing the homework for the next session. The point, however, is in S1's utterance in turn 2 of the extract. She asked the teacher whether or not to write the assignment. This utterance is interpretable as S1's comprehension of the teachers demand, that she has understood what the homework was and she was just asking for more clarifications on its form. But that is not true. Because she is the same student who in Extract 1, turn 3 confessed that she has mistakenly written a conversation instead of an interview. A case of disaffiliation with the teacher's demand due to her misunderstanding of the teacher as a result of the teacher's using $L 2$.

Another point about Extract 2 lies in the second line of the teacher's turn in turn 1. In this turn, Teacher 1 announced to the students the homework for the next session, which consisted of doing the exercises of their workbooks and an additional task, an interview. The point is that to highlight this matter that the students have to do two things for their homework, the teacher used Farsi (L1). While still in the managerial mode, she used Farsi to make the transition from one requirement to the second one. By doing this, she kept the probability of her students misunderstanding her at a very low level. This is evident in Extract 1, when the students, in the following session, were absolutely aware of a second task to carry out as homework even though they did not do it. This is especially evident in S4's account in Extract 1 where she claims that she has not done the required task because she did not know what to do. This account of S4 can be interpreted as her awareness of a second task for homework. Therefore, we can conclude that teacher 1's use of L1 to highlight the transition and attract the students' attention to the fact that there are two assignments has perfectly worked out and the students truly noticed that there are two tasks to be done for homework. 
Another instance of using $\mathrm{L} 1$ in the managerial mode and for attracting the students' attention can be found in Extract 3 below.

\section{Extract 3 (Teacher 2)}

1. $\mathrm{T}$ : the writing on page 63 is the topic of your next writing.

$\rightarrow /$ tr.: let's see what it has for youl

my favorite TV show. Think of your favorite TV show. Answer the questions.

And there is a sample writing for you.

/tr.: see how it has instructed you. The questions that are in the writing for you or the questions I tell you to write for your writings, you are not supposed to just answer those questions. You should use those questions to write a paragraph or two about the topic. Not answering the questions one by one. Your writing skills are getting more advanced and you should move on from writing a sentence to writing a paragraph. Ok, let's see what it has for you./

My favorite TV show

Extract 3, depicts the part of the class in which the teacher (Teacher 2) announced the homework for the next session. We can see that the teacher made use of both English and Farsi in one single turn. The first time she used Farsi she did it to turn the students' attention to what followed. She showed the transition from her own talking to reading from the book by using $L 1$ as an indicator of this transition. The teacher has, most probably, assumed that by using Farsi (L1) she could draw the students' attention more effectively and consequently avoid any repetition or misunderstanding. This assumed conception of this teacher's is perfectly in line with the findings of different studies carried out in the field of second language teaching and learning. Castellotti (1997, as cited in Turnbull \& Arnett, 2002), for instance, suggested that code-switching (CS) is a useful tool for drawing the students' attention. Faltis (1990), in the same vein, identified four areas for using L1 in the classroom, one of which capturing the students' attention.

After making sure that she has her students' attention, the teacher switched to English by reading the book. She did not translate the instructions given in the book assuming that the students could understand it. She maintained the English code and continued "and there is a sample writing for you" assuming that she had her students' attention and that they could understand it fairly. After that she switched to Farsi for the second time to make an important note. By doing this, she, most probably, wanted to make sure that students understood what they were supposed to do, and avoid any kind of misunderstanding and disaffiliation. This teacher, too, like Teacher 1 in Extract 1, seemed to have used Farsi to insure everybody understood the points clearly, so that there would not be any excuses for not knowing what to do in the following session.

To see whether or not this choice of code which was, most probably, based on Teacher 2's preconceptions has worked out, we should see the result of the students' writings in the following session. Quite interestingly, in the next session, when the teacher asked some students to read their paragraphs aloud, they all did a relatively fair job. Except for three students who attempted to answer the questions provided in the task, separately, others' writing pieces had more or less the form of a paragraph. It is worth mentioning that one of the three students whose writing pieces consisted of separate answers to the questions was absent in the previous session when the teacher made the point on how to do such exercises in Extract 3. Extract 4 below which is the transcript of a student reading aloud his paragraph can be good evidence to show that Teacher 2's use of L1 for making this point, in order to insure their comprehension, paid off.

\section{Extract 4 (Teacher 2)}

1. S: my favorite TV show is Avaye Baran. It is made in Iran. I like this show because I like dramas and it's a good TV show. The actors and actresses play good in this movie. I like NAME OF AN ACTOR in this TV show very much.

Overlooking its blunders, one can distinguish the preceding extract as a paragraph. With regard to Teacher 2's remark about the students' answering the questions, we can interpret that these students used to answer the questions which were provided for them as help, separately. This is also evident in the writings of those three students mentioned above. The importance of Extract 4, which is just one example of the paragraphs written by these students, is in that it evidently shows the change in the students' behavior as a result of teacher's use of $L 1$ for making the point.

The fact that this teacher, too, used L1 in the managerial mode for making a point and insuring the students' comprehensibility adds to the generalizability and reliability of studies, such as Castellotti (1997, as cited in Turnbull \& Arnett, 2002), Littlewood and Yu (2011), and others, claiming and/or counting this aspect of $L 1$ use as one of the most important or frequent reasons for using L1 in L2 classrooms.

It goes without saying, however, that we can still argue that this teacher could have used English for explaining the homework at the first place, and then if 
the student did not understand it, she could have translated it, but as in Extract 1, it might be inferred as the teacher's time management technique that she skipped the English part to save the class time for other activities to be covered in that particular session.

The managerial mode occupied nearly 20 percent of the classroom time, on average, from which nearly 12 percent was in Farsi and only about 8 percent was in English. In simple math, three-fifth of the managerial mode of the data for this study was held in Farsi, and only two-fifth of it was held in English. Of course, this is the total amount of use of L1 by both teachers and students, i.e. the percentage of the class which Farsi was used in regardless of who used it. These numbers are amazing considering the advice, and sometimes rules, teachers have to follow to minimize, and sometimes abandon L1 and maximize L2.

Using L1 in order to draw the students' attention and displaying transition is not merely restricted to the managerial mode. Another classroom mode in which the role of L1 can be considered as crucial is the skills and systems mode. This is the mode whose focus, according to Walsh (2011) is to enable learners to produce correct forms and manipulate the target language. This mode is naturally replete with formfocused corrective feedback. Using L1 in this mode, in the data of this study, relied heavily on the subject matter to be taught and learned. If the subject was relatively easy or that the students were more or less familiar with it, then the interactions took the form of sequential IRFs and the use of L1 was more restricted to transition indicators. On the other hand, however, if the subject matter was challenging and difficult for the students, then the extent of L1 use increased and it was used as a tool for explaining the points and decreasing the cognitive load of the learners (Scott, 2008), as well. One instance of using L1 to indicate transition in skills and systems mode can be found in Extract 5 below.

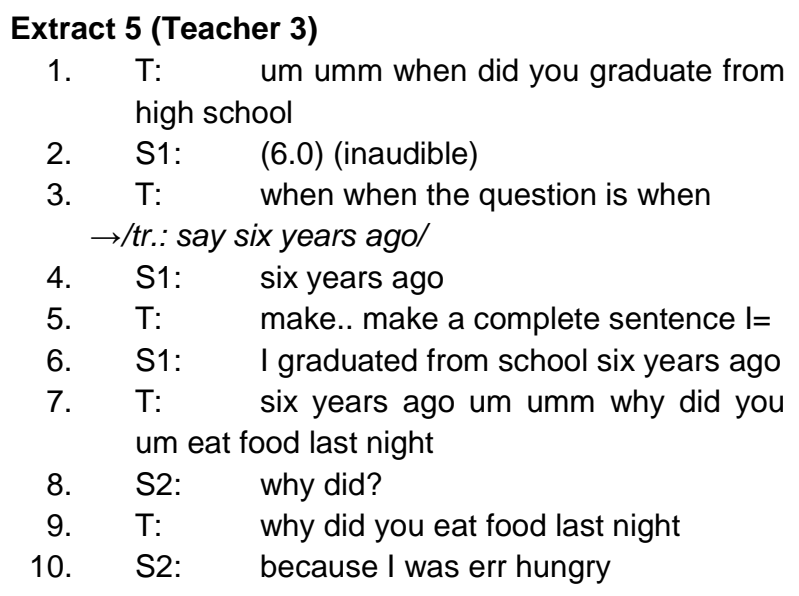

11. $\mathrm{T}$ : yes (because I was hungry I was hungry) umm why STUDENT why are you tired today

12. S3: (7.0) errr

13. T: $\rightarrow$ /tr.: say because because I worked a lot/

14. S3: err because I umm worked very

15. T: much

16. S3: much

Extract 5 is part of a Teacher 3's class in which past tense was being taught. In this part the teacher tried to have students practice the patterns and internalize it. In turns 3 and 13 the teacher guided the students how to answer, or what to answer by telling them the Farsi equivalent and asking them to reproduce it in English; however, he did not seem to rush it. In turn 3, it seems that the student had some difficulty understanding the question; this is interpretable through the six-second pause S1 made before he said the inaudible part of the transcript. The teacher, nonetheless, did not provide a translation of the question word "when," instead he repeated it, putting the emphasis on the word "when" in order not to be mistaken by any other words like "where," and asked the student (S1) to answer hypothetically by saying /tr.:say six years ago/. Hence, the teacher provided the student with both the meaning of the word "when" in the question, and also an answer to the question which the student had to reproduce in English.

In turn 13, the teacher, after a long seven-second silence, presumed that the student (S3) could not answer or she did not know what to answer, so he (the teacher) interfered and helped the student by providing an answer in Farsi and asking her to reproduce it in English.

Eliciting desired structures from the students and encouraging them to produce turns in $\mathrm{L} 2$ can also be seen in other studies such as Üstünel and Seedhouse (2005). They argued that teachers used Turkish (L1) in order to make the students produce the desired structures. In another study, Rolin-lanziti and Brownlie (2002) suggested that $L 1$ is used by teachers to motivate the students to speak the TL in the classroom. Teacher 3's use of Farsi (L1), in this study, insured that the teacher did not provide the students with the English structure when they were supposed to practice it, and at the same time he elicited what he expected to hear from them. He actually induced the students to make the preferred response he desired. This could be considered a valuable asset available for teachers who share the same first language with the students, or who 
are familiar with the students' first language. It can also be seen as an advantage for teachers familiar with their students' L1 over teachers who come from a different L1.

As for the portion of occupying the class time the case was different for the skills and systems mode. On average, skills and systems mode occupied about 23 percent of the classroom interactions from which the percentage of Farsi ranged from 0.5 percent to approximately 20 percent of the whole. That is, in some cases this 23 percent could be divided as 22.5 percent English and only 0.5 percent Farsi. Or it could be seen to be as nearly 20 percent Farsi and only 3 percent English. Because of this vast range and huge difference between the percentages of L1 use in different classes, I decided not to state the average, since it did not seem very expressive of the fact, and opted for stating the two extremes. One reason for this huge difference could be that, whenever a teacher wanted to teach something new, something the students were not familiar with previously, they used Farsi more often to explain it, hence the major part was held in Farsi. However, whenever a teacher wanted to teach something the students were already familiar with, or whenever they wanted to practice the already taught materials, they mostly used English and switched to Farsi very rarely to make some points, hence the major part in English.

The third out of four modes of the classroom is the materials mode. This is probably the most dominating mode in the classroom modes, since there is typically a course book and that book determines everything that goes on in the classroom: the activities, the interactions, and the discussions, if any. The book determines the whole process of instruction in the class: the grammar and the vocabulary taught, all were, as if, dictated to the teacher by the book, in the classes observed. This dominance is also evident in Table 2 below, demonstrating the allocation of about $57 \%$ of the classroom time to this mode. However, the percentage of L1 use in this mode was not as conspicuous as the previously mentioned two modes: about 8 percent of the whole. In simple words, from the total of 57 percent, about 49 percent was held in English, and nearly 8 percent in Farsi. The reason for this could be seen in the interactions taking place in this mode which are mostly short, often one word, and that whatever the teachers say is mostly written in the books and students can read them and understand them better, hence there appears to be no need to switch to Farsi.

The use of L1 in this mode, too, can be considered twofold: making students understand, and attracting their attention. This could be considered the mode in which the least amount of $L 1$ is used. This may be due to the nature of its interactional feature, which is the IRF sequence. The turns are mostly short, may be a single word in some instances, and the words used are either known to the learners or they are presented to the students in the books in the form of "complete the sentences with the words in parentheses." Therefore, very little genuine interaction happens that is not scripted and comes from the students' own initiatives. However, when there come the times that there are some interactions the students and the teachers seem to avoid missing the opportunity of using their L1 as in Extract 6 below.

\section{Extract 6 (Teacher 1)}

1. $\mathrm{T}$ : we will check er... number three, I always skip the sad parts of the movies skip. STUDENT 1.

2. S1: do or have something that you should do or have to

3. T: and you mean letter? (.) no no yes ok you find the dictionary meaning? And which one $a$ to $h$ is the correct answer or definition for skip Yes STUDENT 2 (1.0) STUDENT 2.

4. S2: /tr.: we have found the dictionary meaning/

5. T: uhuh, and you didn't find anything for (2.0) STUDENT3 what's your idea? No idea. STUDENT4 (12.0)

$\rightarrow /$ tr.: so what is the answer for it/ number three.

6. Ss: b....b.....b to not watch something

Extract 6 is part of a class in which an exercise was being done in the class. The students were supposed to have looked up the meanings of the new words in their dictionaries and then match the words with the corresponding definitions given in their books. In turn 1 the teacher asked for a matching definition to which students had to provide a letter from $A$ to $H$ that matched the definition with the word, but the student (S1) provided a dictionary meaning for it which was disaffiliative with the teacher's request. Then in turn 3 the teacher asked for the answer from another student (S2). S2 also showed disaffiliation by commenting that she, too, had just found the dictionary meaning, as she said "I have found the dictionary meaning," and she has not matched the word with the definition. Then again, in turn 5 the teacher tried some other students, but when she did not get any answers she switched to Farsi, desperately, perhaps, and said /tr.: so what is the answer for it/. That seemed like an impetus that triggered the students and they finally provided the answer for the question. This seemingly small switch to Farsi made a difference between affiliation and disaffiliation. By using L1 the teacher made the students 
answer the way she wanted. It appears that the students had difficulty understanding the teacher and therefore the teacher switched to Farsi in order to make the students aware of what she was looking for. As in Extract 5 above, use of $L 1$ resulted in affiliation of the students' response with the teacher's demand. Such utilization of $\mathrm{L} 1$ can also be seen in Üstünel and Seedhouse (2005). As one of the findings of their study, they found that teachers use $L 1$ in order to insure the affiliation of their students' responses with their demands.

Another instance of using $\mathrm{L} 1$ in the materials mode is for attracting the students' attention. One such instance can be found in Extract 7 below.

\section{Extract 7 (Teacher 2)}

1. T: I don't know anything about Iranian football.

$\rightarrow /$ tr.: ok, let's move on to/ reading

Before listening to the reading, what do you know about the reality show?

((writing on the board)) reality show

2. S3: er...it...er...it..er...shows the person...the real..realli:z /tr.: no/ really=

3. S: =real person

4. T: realities?

5. S3: uh huh,

6. T: uh huh

7. S3: real person /tr.:yes...no/ people's realities life.

As can be seen in Extract 7, the teacher used L1 equivalent of a, seemingly, very simple English phrase "ok, let's move on to." Here the intention of the teacher must have been something other than making students comprehend what was said to them, since it seemed crystal clear, based on the researcher's own evaluation of the class, when shooting the classes, their level of proficiency, and the book the students were studying, that the students could not have any difficulty understanding "ok, let's move on to the reading part." So, the teacher's use of the $L 1$ equivalent must have intended to capture the students' attention to what followed it. The teacher seemed to believe that if she used Farsi, it could more easily and more effectively attract students' attention. In this occasion, it may be clear that the teacher could not have any difficulty language difficulty - producing the English equivalent. So the only possible explanation for using Farsi was to make students notice what she was going to say following the Farsi phrase. Examples like this are very abundant through the data among different teachers. Words or phrases like /tr.: ok/ and /tr.: now/ are among the most frequently used discourse markers that show the use of L1 for the sake of capturing students' attention and also to announce clearly the transitions from one mode or activity to another, or within one mode or activity. The point about this extract is that the students noticed the transition, thanks to the teacher's use of $\mathrm{L} 1$, terminated the previous discussion and started to talk about the new topic raised by the teacher. As in Extracts 2 and 5, it can be seen that the teacher's aim to attract the students' attention by using $\mathrm{L} 1$ is fulfilled in this extract.

The last of the four modes of the classroom, discussed in this paper, is the classroom context mode. According to Walsh (2011), as mentioned earlier, this is the mode in which there are more opportunities for genuine interactions. The teacher plays a less prominent role and allows the students to take the initiatives and control the flow of the conversations themselves. This mode provides the opportunity for students to use what they have learned. The teacher's taking a "back seat" role allows the students to learn how to take turns in talking, how to show they want an opportunity to talk, and lots of other things that they would not otherwise learn, since it is always the teacher who determines who to talk, what to talk, and how much to talk. Therefore, this mode, according to CLT, must be very important.

All the above mentioned emphasize how important the classroom context mode is, nevertheless, in complete surprise - maybe shock would be a more appropriate word! - there was no classroom context mode to be found in the whole classes observed. No teacher, without any exception, provided the class with such opportunity.

This lack, if I may call it, may be due to the bookoriented nature of the classes observed and that the whole process of teaching and learning is determined by the books used in the courses. Another reason for this lack may be the amount of material that the teachers have to cover during each course and that does not allow them to dedicate some time to such conversations and activities. Of course, this cannot justify the inexistence of the classroom context mode. Maybe this is why the so called "Free discussion" classes exist, in which people discuss different topics and share their ideas and opinions with others. This might show the recognition of the importance of this mode and its interactions in language learning, nonetheless, it requires the learners to attend to another class, which means one needs to spend more money and time. This might be a controversial issue but its discussion is unrelated to the topic of this study.

All in all, the reasons teachers use $\mathrm{L} 1$ are summarized in Table 3 . Teachers use L1 (a) to make 
sure students understand what was said to them completely; (b) to turn students' attention to what followed; (c) to make sure students would not forget what was said to them; (d) to elicit the desired structure; and (e) to teach grammar and/or vocabulary; (f) to display a transition from one activity to another or within an activity; and (g) to save the time of the class. There could, of course, be some other reasons for both students and teachers to use L1 as establishing a rapport as mentioned in Mora Pablo et al. (2011), or providing scaffolded help as in Antón and DiCamilla (1998) and many others.

\section{DISCUSSION AND CONCLUSION}

Although these three teachers were advised not to use L1 in their classes or minimize its use, and not to allow students to use it, a great portion of the classes (as depicted in Table 2) were in Farsi.

This is in line with studies claiming L1 use is unavoidable in EFL context (Chen \& Hird, 2006; Cook, 2001; Song, 2009).

Table 2 (The average percentage of each classroom mode)

\begin{tabular}{cccc} 
Classroom modes & $\begin{array}{c}\text { Total percentage } \\
\text { (average) }\end{array}$ & $\begin{array}{c}\text { Percentage of Farsi } \\
\text { used (average) }\end{array}$ & $\begin{array}{c}\text { Percentage of English } \\
\text { used (average) }\end{array}$ \\
\hline Managerial mode & $\sim 20 \%$ & $\sim 12 \%$ & $\sim 8 \%$ \\
\hline $\begin{array}{c}\text { Material mode } \\
\begin{array}{c}\text { Skills and systems } \\
\text { mode }\end{array}\end{array}$ & $\sim 57 \%$ & $\sim 8 \%$ & $\sim 49 \%$ \\
\hline $\begin{array}{c}\text { Classroom context } \\
\text { mode }\end{array}$ & $\sim 23 \%$ & $\sim 0.5-\sim 20 \%$ & $\sim 3 \%$ \\
Total & ------ & ------ & ------ \\
\hline
\end{tabular}

Table 3 (The reasons for using L1 in each mode)

\begin{tabular}{cl}
\hline \multicolumn{1}{c}{ Modes } & \multicolumn{1}{c}{ Reasons } \\
\hline skills and & $\begin{array}{l}\text { 1. To draw students' attention to what followed. } \\
\text { 2. To make sure students understand what was said to them. } \\
\text { 3. To explain the difficult and important grammatical points. } \\
\text { 4. To save the time of the class. } \\
\text { 5. To elicit the desired structure. }\end{array}$ \\
\hline Managerial mode & $\begin{array}{l}\text { 1. To draw students' attention to what followed. } \\
\text { 2. To make sure students understand what was said to them. } \\
\text { 3. To display transitions from one activity to another (or within one single activity). } \\
\text { 4. To save the time of the class. }\end{array}$ \\
\hline Classroom & $\begin{array}{l}\text { 1. To draw students' attention to what followed. } \\
\text { 2. To make sure students understand what was said to them. } \\
\text { 3. To save the time of the class. }\end{array}$ \\
\hline
\end{tabular}

Teachers use L1 for various reasons: (a) to make sure students understand what was said to them completely; (b) to turn students' attention to what followed; (c) to make sure students would not forget what was said to them; (d) to elicit the desired structure; (e) to teach grammar; (f) to display a transition from one activity to another; and probably ( $\mathrm{g}$ ) to save the time of the class. It is apparent that in some cases the teachers made use of L1 to convey the meaning in the quickest form possible in order to save the time of the class. All these purposes can be gathered together under the umbrella notion of preference. This means that, teachers switch to $\mathrm{L} 1$ for the preceding reasons to make sure the preferred response to their questions, requests, demands and so on.

As can be seen in Table 3, reasons like grabbing students' attention and making sure of their comprehension are recurring invariably in almost 
(because there was no classroom context mode) all the classroom modes. And reasons like explaining difficult grammar and/or vocabulary and eliciting the desired structure or utterance were constrained to the skills and systems mode. Based on these findings, one may reason that teachers can educate their learners about transitional markers in L2 explicitly in early levels, and

\section{REFERENCES}

Antón, M., \& DiCamilla, F. (1998). Socio-cognitive functions of $L 1$ collaborative interaction in the L2 classroom. Canadian Modern Language Review, 54(3), 314-342.

Atkinson, D. (1987). The mother tongue in the classroom: A neglected resource? ELT journal, 41(4), 241-247.

Brooks-Lewis, K. A. (2009). Adult learners' perceptions of the incorporation of their L1 in foreign language teaching and learning. Applied Linguistics, 30(2), 216-235.

Chen, R., \& Hird, B. (2006). Codeswitching in EFL group work in China. Language, Culture and Curriculum, 19(2), 208-219.

Cook, V. (2001). Using the first language in the classroom. Canadian Modern Language Review, 57(3), 402-423.

De La Campa, J. C., \& Nassaji, H. (2009). The amount, purpose, and reasons for using $L 1$ in L2 classrooms. Foreign Language Annals, 42(4), 742-759.

Dickson, P. (1996). Using the target language: a view from the classroom. Slough: NFER.

Faltis, C. (1990). New directions in bilingual research design: The study of interactive decision making. Language distribution issues in bilingual schooling (56), 45.

Franklin, C. E. (1990). Teaching in the target language: problems and prospects. Language Learning Journal, 2(1), 20-24.

Jefferson, G. (1983). Issues in the transcription of naturally occurring talk: Caricature versus capturing pronunciational particulars. Tilburg Papers in Language and Literature, 34, 112.

Language Use and Social Interaction (PDF Download Available). Available from: https://www.researchgate.net/publication/299 696013_Language_Use_and_Social_Interac tion [accessed Aug 21, 2017].

Kraemer, A. (2006). Teachers' use of English in communicative German language classrooms: A qualitative analysis. Foreign Language Annals, 39(3), 435-450.

Littlewood, W., \& Yu, B. (2011). First language and target language in the foreign language classroom. Language Teaching, 44(01), 6477.

Markee, N., \& Kasper, G. (2004). Classroom talks: An introduction. The Modern Language Journal, 88(4), 491-500. make them sensitive to these utterances, so that teachers would not have to use $L 1$ for such reasons. By doing this, the use of $L 1$ in $L 2$ classes can fall into its minimum: explaining difficult grammar and vocabulary, and eliciting the desired structure or utterance. The former, nonetheless, can fade away as the proficiency level of the learners increases (Woodall, 2002).

Mora Pablo, I., Lengeling, M. M., Rubio Zenil, B., Crawford, T., \& Goodwin, D. (2011). Students and teachers' reasons for using the first language within the foreign language classroom (French and English) in Central Mexico. Profile Issues in Teachers Professional Development, 13(2), 113-129.

Rolin-lanziti, J., \& Brownlie, S. (2002). Teacher use of learners' native language in the foreign language classroom. Canadian Modern Language Review, 58(3), 402-426.

Samar, R. G., \& Moradkhani, S. (2014). Codeswitching in the language classroom: a study of four EFL teachers' cognition. RELC Journal, 45(2), 151-164.

Scott, V. M. (2008). What's the problem? L2 Learners' USE of the L1 during consciousness-raising, form-focused tasks. The Modern Language Journal, 92(1), 100-113.

Seedhouse, P. (2004). The organization of turn taking and sequence in language classrooms. Language learning, 54(S1), 101-140.

Seedhouse, P. (2005). Conversation analysis and language learning. Language Teaching, 38(04), 165-187.

Song, Y. (2009). An investigation into L2 teacher beliefs about L1 in China.

Ten Have, P. (2007). Doing conversation analysis: $A$ practical guide. london: Sage.

Turnbull, M., \& Arnett, K. (2002). Teachers'uses of the target and first languages in second and foreign language classrooms. Annual review of applied linguistics, 22, 204-218.

Üstünel, E., \& Seedhouse, P. (2005). Why that, in that language, right now? Code-switching and pedagogical focus. International Journal of Applied Linguistics, 15(3), 302-325.

Walsh, S. (2011). Exploring classroom discourse: Language in action. London: Routledge.

Warford, M. K. (2007). L1 vs. L2 in the foreign language classroom: new findings. The NECTFL Review, 60, 50-67.

Wells, G. (1998). Using L1 to master L2: A response to Anton and DiCamilla's' Socio-cognitive functions of $L 1$ collaborative interaction in the L2 classroom'. Canadian Modern Language Review, 54(3), 343-353.

Wong, J. (2002). " Applying" conversation analysis in applied linguistics: Evaluating dialogue in English as a second language textbooks. IRAL, 40(1), 37-60. 
Khonamri, F., \& Khonamri, F.

Woodall, B. R. (2002). Language-switching: Using the first language while writing in a second language. Journal of Second Language

Writing, 11(1), 7-28. 